\title{
La regla de oro en la Constitución polaca de 1997 y su influencia social y económica
}

\author{
Rubén Darío Torres Kumbrían \\ Profesor Contratado Doctor de la Facultad de Derecho \\ Universidad Nacional de Educación a Distancia \\ $\mathrm{y}$ \\ Juan de Dios Izquierdo Collado \\ Profesor Titular de la Facultad de Derecho \\ Universidad Nacional de Educación a Distancia
}

Recibido: 20.02 .2012

Aceptado: 02.03.2012

Resumen: Polonia implantó la regla de oro en su Constitución de 1997. La transición política y económica polaca, el cumplimiento de los Criterios de Copenhague de 1993 y la adhesión de Polonia a la Unión Europea constituyen los antecedentes previos que crearon las condiciones objetivas para la implantación de la regla de oro en la constitución. El Capítulo X denominado Finanzas Públicas establece un control efectivo de la elaboración y ejecución de presupuestos estatales equilibrados. Los mecanismos presupuestarios están garantizados por el Parlamento, el Consejo de Política Monetaria, el Tribunal de Cuentas y otros actores institucionales. Otras claves fundamentales es el establecimiento de garantías frente a contingencias de bloqueo legislativo, de resoluciones y de reformas constitucionales, de incremento del déficit público y de la deuda soberana. La regla de oro junto a otros factores, han logrado que Polonia sea inmune en un grado considerable a la crisis financiera. El país goza de un crecimiento económico, es atractivo para los inversores, corrige los desequilibrios y prosigue su proceso de cohesión económica, social y territorial.

Palabras Clave: Regla de Oro, Constitución de 1997, Unión Europea, presupuestos estatales equilibrados, Capítulo X, garantías, Parlamento, Consejo de Política Monetaria, Tribunal de Cuentas, inmune a la crisis financiera, proceso de cohesión, económica, social y territorial.

Summary: Poland introduced the golden rule in its Constitution of 1997. The Polish political and economic transition, compliance with the Copenhagen criteria of 1993 and the accession of Poland to the European Union are the previous history that created the objective conditions for the implementation of the golden rule in the constitution. Chapter X called Public Finance provides effective control of the development and implementation of balanced state budgets. Budgetary arrangements are guaranteed by the Parliament, the Monetary Policy Council, the Court of Auditors and other institutional actors. Other fundamental key is to establish safeguards against lock contingencies legislation, resolutions and constitutional reforms, and increased the deficit and sovereign debt. The golden rule along with other factors, have made Poland is immune to the financial 
crisis. The country enjoys economic growth, is attractive to investors, corrects imbalances and continuing the process of economic, social and territorial cohesion.

Key words: Golden rule, Constitution of 1997, European Union, balanced state budgets, Chapter X, safeguards, European Union, Parliament, the Monetary Policy Council, Court of Auditors, immune to the financial crisis, process of economic, social and territorial cohesion.

Sumario: I. La cumbre europea de Bruselas y la regla de oro.--II. Los antecedentes de la regla de oro polaca. II.1. Transición a la democracia. II.2. La transición económica. II.3. Criterios de Copenhague: vía a la adhesión de Polonia a la UE. II.4. La culminación de la adhesión polaca a la Unión Europea.-III. La Constitución de 1997.-IV. Capítulo X: finanzas públicas. IV.1. Recursos, obligaciones, endeudamiento, préstamos, garantías y cauciones financieras. IV.2. Ingresos del Estado y gestión de los activos del Tesoro. IV.3. Procedimiento legislativo y de ejecución de los Presupuestos. IV.4. Incrementos o reducciones de ingresos y la garantía de impedir desviaciones presupuestarias al alza. IV.5. Iniciativa legislativa presupuestaria exclusiva del Consejo de Ministros. IV.6. Supuesto de resolución sobre la constitucionalidad de la ley presupuestaria y otras garantías preventivas. IV.7. El control parlamentario de la ejecución del presupuesto. IV.8. El Consejo de Política Monetaria.- - V. Los procedimientos de reforma constitucional garantizan la vigencia de la regla de oro.- - VI. El nik y el control del proceso presupuestario.-VII. Conclusiones.

\section{LA CUMBRE EUROPEA DE BRUSELAS Y LA REGLA DE ORO}

La Cumbre de Bruselas de diciembre de 2011 ha impulsado a los Estados Miembros de la UE a abrazar con carácter definitivo la denominada Regla de Oro. La medida se puede definir como una disposición de rango constitucional consagrada a la finalidad de establecer una tendencia equilibrada entre gastos e ingresos que posibilite limitar el crecimiento de las deudas soberanas estatales y los déficit públicos. El objetivo normativo es lograr en el medio y largo plazo unas finanzas públicas sostenibles, garantizadas, probablemente, por un nuevo Tratado de la $\mathrm{UE}^{1}$.

La adopción constitucional de la disposición no garantiza por si misma la praxis de una política de gastos e ingresos equilibrada a través de ajustes estructurales. Por esta razón en la Cumbre de Bruselas se acordó la incorpo-

${ }^{1}$ CONSEJO EUROPEO, Bruselas, 9 de diciembre de 2011, Declaración de los Jefes de Estado y de Gobierno de la zona euro. Los efectos de la Cumbre en los inicios de enero de 2012 están influyendo en los trabajos preparatorios del nuevo Tratado de la UE. El devenir político europeo parece dirigirse a ampliar el margen de maniobra del Tribunal de Justicia, que podría actuar en caso de incumplimiento de todas las provisiones respecto a la disciplina presupuestaria. En el borrador inicial solo estaba previsto que se pronunciara sobre si la regla de oro se ha consagrado adecuadamente en las constituciones. Otro cambio 
ración de mecanismos estatales y comunitarios que garanticen la supervisión del cumplimiento de la finalidad normativa.

La imposición normativa de la adopción y cumplimiento de la regla de oro a escala comunitaria, puede ser analizada como la constatación del fracaso de las resistencias anacrónicas a ceder parcelas de soberanías nacionales en ámbitos donde la globalización financiera ostenta una posición dominante, a la vez que una teórica garantía de vigencia efectiva de la cohesión económica, social y territorial consagrada por el Tratado del Lisboa y los tratados europeos precedentes.

En el caso polaco, la evidencia empírica parece revelar que el Capítulo X de la Constitución de la III República de 1997, ha sido la piedra angular de un modelo de Finanzas Publicas que ha brindado un grado elevado de inmunidad contra la crisis, un modelo que hasta el momento parece ser sostenible en cuanto a su capacidad de establecer tendencias de equilibrio presupuestario, de competitividad, de atracción de inversiones y de impulsar un proceso de cohesión económica, social y territorial. Los antecedentes del caso constitucional polaco se pueden situar en su transición política y económica, y en la revolución silenciosa que supuso la adopción y puesta en práctica de los Criterios de Copenhague de 1993 y en la adhesión a la UE².

\section{LOS ANTECEDENTES DE LA REGLA DE ORO POLACA}

\section{II.1. Transición a la democracia}

Polonia puede ser considerada inequívocamente como un país precursor del constitucionalismo europeo. La Constitución del 3 de mayo de 1791 estuvo dotada del humus original del constitucionalismo liberal, que perduró invernado en la cultura política polaca a pesar de los dramáticos avatares históricos que sufrió el país durante los siglos XIX y XX³

propuesto en el texto revisado se refiere al número de países de la eurozona que deben tener ratificado el tratado para que pueda entrar en vigor. El tercer cambio introducido en el texto es una propuesta para incluir, en un plazo de cinco años, el pacto fiscal en los tratados de la UE, lo que significa que el Reino Unido, que se excluyó del pacto, tendría que dar su visto bueno. Precisamente la negativa de Londres a participar en el pacto ha impedido a los demás países miembros avanzar en una modificación de los tratados y les ha obligado a proceder con un tratado intergubernamental o internacional.http:/www.consilium.europa.eu/uedocs/cms_data/docs/pressdata/es/ec/126673.pdf. Consultado el 7 de enero de 2012.

${ }^{2}$ Torres Kumbrian, R.D. La cohesión, económica, social y territorial europea: Polonia laboratorio principal de su viabilidad futura, en "Polonia y España ante el futuro de la Unión Europea", Edita UCLM-Warsaw University Centre for Europe, L. Popular, Albacete, 2003.

${ }^{3}$ A fines del siglo XVIII se consagraron tres constituciones consideradas como las primeras constituciones modernas en el mundo. La Constitución Americana del 17 de Septiembre de 1787. La segunda en el mundo y la primera en Europa fue la Constitución Polaca del 3 de Mayo de 1791, precediendo a la Constitución Francesa de Setiembre por algunos meses. Todas ellas reflejaban los cambios políticos, sociales y económicos venideros. 
El sui generis constitucional liberal progresista polaco resurge de las cenizas del nazismo y del comunismo como un Ave Fénix, cuyo vuelo de regreso a la casa común europea se inicia en un proceso de transición democrática que nace una década antes del derribo del Muro de Berlín, coincidiendo con la primera visita de Juan Pablo II a Varsovia en $1979^{4}$.

Las elecciones fundacionales de la nueva democracia polaca se celebraron en una doble vuelta los días 4 y 18 de junio de 1989. Las elecciones eran el resultado de las llamadas negociaciones de la Mesa Redonda, que reservaban de antemano el 65\% de los escaños en la Cámara Baja (Sejm) al oficial Partido Obrero Unificado Polaco (PZPR) y a sus partidos satélites, pero creaban un Senado para el que las elecciones fueran plenamente competitivas. Estas elecciones semidemocráticas arrojaron un arrollador triunfo de la coalición Solidaridad, que logró el total de los escaños competitivos en la Sejm y 99 de los 100 escaños del Senado. Tras un pacto en 1990, Jaruzelski abandonó la presidencia, y en diciembre Walesa fue elegido nuevo Presidente por el voto directo de los ciudadanos ${ }^{5}$.

\section{II.2. La transición económica}

El principal problema de la Polonia independiente fue de índole económica. En 1990 la hiperinflación, fuera de control, llegó a un 500\%; la gran deuda externa no permitía ningún tipo de inversiones.

Los factores como el paro encubierto, la industria anticuada y poco rentable, y el sector agrícola preponderante en el Producto Interior Bruto polaco, se visualizaban como obstáculos casi insalvables para emprender una transición económica hacia el libre mercado. La reflexión retrospectiva de Hanna Suchocka es significativa al respecto: "En un principio, nadie pensaba en la privatización y liquidación del enorme y obsoleto conglomerado de empresas estatales, algo que habría chocado con los intereses de los trabajadores, principales actores de Solidaridad. Según la opinión dominante en 1980, el nuevo sistema económico debería estar basado en una reforma parcial del socialismo" 6 .

${ }^{4}$ Torres Kumbrían, R. D. Del Derribo del Muro de Berlín al nacimiento de la Unión Europea de los Veinticinco, en La Musa, Volumen 3, páginas 55-62, Editorial L. PopularFacultad de Humanidades de la UCLM, ISSN 1579-2803, 2005.

${ }^{5}$ Kolarska-Bobinska, L. (1994), "Social interests and their political representation: Poland in transition", British Journal of Sociology “, London, 1994.

${ }^{6}$ Hanna Suchocka fue Primera Ministra de Polonia, de julio de 1992 a octubre de 1993. De 1997 a 2000, fue Ministra de Justicia, posteriormente fue Embajadora de Polonia ante la Santa Sede. EL párrafo citado corresponde a su intervención en la Fundación FRIDE, el 5 de marzo de 2002, en Seminario sobre Transición y Consolidación Democráticas 2001 -2002, Mesa redonda: La transición a la democracia en Polonia, 5 de marzo de 2002. http://search.iminent.com/Search TheWeb/v4/3082/homepage/Default.aspx. Consultado el 30 de noviembre de 2011. 
La ley de liberalización de las actividades económicas de 1988 y la liberalización de los precios de 1989 no produjeron los resultados esperados y se optó por el Plan de Balcerowicz ${ }^{7}$.

El proceso de privatización resultó ser más complejo en el sector de la industria pesada, por su gran impacto social excluyente en el corto, medio y largo plazo. Esa consecuencia ha llevado a que el proceso de privatización de los sectores siderúrgico, químico y de maquinaria pesada se encuentre inconcluso $^{8}$.

\section{II.3. Criterios de Copenhague: vía a la adhesión de Polonia a la UE}

La breve trayectoria polaca desde el proceso de preadhesión hasta su condición actual de Estado miembro de la Unión Europea, constituye un indicador objetivo de la validez de la Política de Cohesión Económica, Social y Territorial Europea, cuando los sucesivos gobiernos nacionales polacos han demostrado contribuir y no dificultar el objetivo de la cohesión a través del cumplimiento del equilibrio de las finanzas públicas tal como establecen desde el artículo 216 hasta el 227 del Capítulo X de la Constitución de $1997^{9}$.

En 1993, el Consejo Europeo de Copenhague abrió la perspectiva de la ampliación a los países de Europa Central y Oriental a través de la Política Preadhesión que sirvió, de forma limitada, de estimulo a los entonces Estados candidatos. Los criterios de Copenhague fueron la base estratégica política, normativa y económica al establecer las condiciones de la adhesión. Se pueden definir como los antecedentes o requisitos políticos, económicos, normativos y de capacidades institucionales y administrativas ineludibles a la consagración constitucional de la regla de oro y su efectivo desempeño posterior en Polonia ${ }^{10}$.

${ }^{7}$ El resultado fue la estabilización de la economía polaca y la apertura de sus mercados al exterior. El proceso de transición económica implicó la reforma el sistema bancario y de la política financiera y crediticia, que posibilitó la creación del mercado de capitales y del mercado laboral.

http://www.paiz.gov.pl/index/?id=d714d2c5a796d5814c565d78dd16188d. Consultado el 2 de diciembre de 2011.

${ }^{8}$ Zulawska Ursula. Las Privatizaciones en los Países Socialistas

http://www.azc.uam.mx/publicaciones/gestion/numl/doc10.html. Consultado el 30 de noviembre de 2011.

${ }^{9}$ Torres Kumbrian, R. D. Evolución y Perspectivas de la Cohesión Económica y Social frente al reto de la ampliación comunitaria, FLORES JUBERÍAS (coord.) "Cuadernos Constitucionales de la Cátedra Fadrique Furió Ceriol" 43/44, Edita Departamento de Derecho Constitucional, Ciencia Política y de la Administración de la Universidad de Valencia, Valencia, 2003.

${ }^{10}$ Izquierdo, J. "Título XVII: Cohesión Económica y Social” en "Exégesis Conjunta de los Tratados Vigentes y Constitucional Europeos.” Editorial Aranzadi, Colección CIVITAS. Madrid 2005 
Los criterios políticos se referían a la estabilidad de las instituciones que garanticen la democracia, el Estado de Derecho, los derechos humanos y el respeto a las minorías; el criterio del acervo se definió como la capacidad de asumir las obligaciones de la adhesión, incluida la observancia de los fines de la unión política, económica y monetaria. Los criterios económicos exigían una economía de mercado en funcionamiento y la capacidad de hacer frente a la presión de la competencia y a las fuerzas del mercado dentro de la Unión, ajustándose a los principios aplicables a las políticas económicas consagrados en el Tratado CE por el Tratado de Maastricht, que entró en vigor el 1 de noviembre de $1993^{11}$.

Desde sus dictámenes de 1997 sobre las solicitudes de adhesión de los países de Europa Central y Oriental, la Comisión Europea fue evaluando anualmente los avances conseguidos por el país. La tendencia polaca de cumplimiento de los criterios de adhesión y adopción del acervo comunitario, posibilitó la aceleración de las reformas internas exigidas por la $\mathrm{UE}^{12}$.

Los argumentos históricos, económicos y políticos que abogaron en favor de la ampliación fueron harto convincentes. Podemos afirmar que a pesar de las dificultades lógicas de un proceso de adhesión, la ampliación a una UE-27 fue un derecho conquistado por parte de los nuevos socios de la Unión y que en modo alguno puede considerarse como un privilegio otorgado. En el caso polaco, debido a su posición geoestratégica, su dimensión territorial, su dimensión demográfica y el tamaño de su economía era especialmente significativo ${ }^{13}$.

\section{II.4. La culminación de la adhesión polaca a la Unión Europea}

El Tratado de Niza otorgó a la Unión Europea una salida constitucional transitoria que posibilitó la ampliación, al tiempo que inició el proceso constituyente con la Declaración 23 relativa al futuro de la Unión, que tras el intento truncado de Constitución Europea, se tradujo en el vigente Tratado de Lisboa, cuyo carácter efímero se vincula a los efectos de las crisis financiera internacional ${ }^{14}$.

Polonia fue el país que mayores inquietudes despertaba en la UE de los Quince. Sus 312.677 kilómetros cuadrados, su dimensión demográfica de 38

${ }^{11}$ Tratado de la Unión Europea. El Tratado de Maastricht introdujo nuevas formas de cooperación entre los gobiernos de los Estados miembros. Al añadir esta cooperación intergubernamental al sistema "comunitario" existente, el Tratado de Maastricht creó una nueva estructura con tres "pilares", de naturaleza tanto económica como política: es la denominada "Unión Europea” (UE). Diario Oficial n C 191 de 29 julio 1992.

${ }^{12}$ COM (2002) "Hacia una Unión Europea ampliada - Documento de estrategia e informe de la Comisión Europea sobre los progresos de cada uno de los países candidatos en la vía de la adhesión"

${ }^{13}$ Izquierdo, Juan de Dios. La cohesión económica y social ante el Segundo Informe Trienal de la Comisión. “Sistema 160”, Editorial Sistema, Madrid. 2001.

${ }^{14}$ Torres Kumbrian, R. D. La constitución europea y los nuevos estados miembros de la Unión Europea. "Teoría y Realidad Constitucional”, Editorial Centro de Estudios Ramón Areces, Madrid, 2005. 
millones de personas, un $38 \%$ de la población situada en el ámbito rural, un $62 \%$ ubicada en los ámbitos urbanos de Varsovia, Cracovia, Łódź, Szczecin. El peso del sector primario en la economía se aproximaba al $40 \%$ de su PIB, los déficits de capacidades institucionales y administrativas, sobre todo de ámbito regional eran considerables. Sin embargo, el proceso de transformación se aceleró gracias a la perspectiva de la ampliación, aunque las negociaciones de adhesión se basaron en los principios de los méritos propios, la diferenciación y el logro del nivel necesario.

Durante las negociaciones de adhesión, Polonia cerró provisionalmente 27 capítulos. En general, el país cumplió los compromisos asumidos en las negociaciones, aunque se produjeron retrasos en aspectos relativos a la agricultura, la pesca y el medio ambiente. La Comisión consideró que Polonia estaba en situación de asumir las obligaciones derivadas de la adhesión con arreglo al calendario previsto. En el período previo a su adhesión el país continuó preparándose con arreglo a sus compromisos en las negociaciones de adhesión. El 16 de abril de 2003 se firmó en Atenas el Tratado de Adhesión a la Unión Europea de Polonia ${ }^{15}$.

\section{LA CONSTITUCIÓN DE 1997}

La Constitución de la República de Polonia de 1997 es el documento legal de mayor rango y la base del ordenamiento del Estado, dotada de una estructura simple y compuesta por un preámbulo, 13 capítulos y 243 artículos, retoma la tradición precursora liberal del país, encarnada por su Constitución de 3 de mayo de $1791^{16}$.

Esta Ley Fundamental garantiza las libertades y el respeto a los derechos humanos, determina las relaciones entre el poder legislativo, ejecutivo y judicial, decide la forma y el procedimiento para la elección o nombramiento de los órganos más importantes del Estado, tales como la Cámara de los Diputados, el Senado, el Jefe del Estado y el Consejo de Ministros. Determina directamente el modelo de sistema judicial, de gobierno regional, y de los órganos del control estatal.

La Carta Magna polaca regula también los asuntos relacionados con la administración estatal, el presupuesto del Estado y las situaciones especiales como puede ser por ejemplo el estado de excepción ${ }^{17}$.

${ }^{15}$ Tratado de Adhesión a la Unión Europea. en Diario Oficial n ${ }^{\circ}$ L 236 de 23/09/2003.

${ }^{16}$ Konstytucja Trzeciego Maja, es la Constitución de 3 de mayo de 1791, también denomina, o Ustawa Rz dowao Ley del Gobierno, es reconocida como la primer Constitución en Europa y la segunda a en el nivel mundial, después de la de los Estados Unidos de Norte América. http://es.poland.gov.pl/Constitucion,1143.html. Consultado el 4 de diciembre de 2011.

${ }^{17}$ Konstytucja Rzeczypospolitej Polskiej z dnia 2 kwietnia 1997 r. uchwalona przez Zgromadzenie Narodowe w dniu 2 kwietnia 1997 r., przyj ta przez Naród w referendum konstytucyjnym w dniu 25 maja 1997 r., podpisana przez Prezydenta Rzeczypospolitej Polskiej w dniu 16 lipca 1997 r.» sejm.gov.pl. Consultado el 14 de dicembre de 2011. 
La Constitución de la III República de Polonia fue aprobada el 2 de abril de 1997 por la Asamblea Nacional, es decir, por el debate parlamentario conjunto de ambas Cámaras. Fue aceptada por el pueblo polaco en el referéndum constitucional del 25 de mayo del mismo año. El 16 de julio de 1997 fue firmada por el Presidente de la República de Polonia, quien entonces era Aleksander Kwaśniewski, y entró en vigor el 17 de octubre y desde entonces sigue vigente.

En el periodo anterior a la aprobación de la Constitución actual, se aplicaba la llamada Pequeña Constitución, que modificó las normas más importantes de las leyes fundamentales introducidas durante el periodo estalinista, vigentes desde el año 1952, lo que permitió el funcionamiento legal del Estado polaco durante los años de la transición democrática y económica desarrollada durante el periodo 1990-97.

La Constitución de 1997 está dotada de un nivel de garantías homologable a las constituciones europeas más avanzadas en todos los ámbitos, incluyendo el económico, aunque puede definirse como una constitución precursora en el contexto de la Unión Europea, al garantizar una tendencia de equilibrio de ingresos y gastos, a través de su Capítulo X, denominado Finanzas Públicas.

Todos los órganos del Estado polaco deben contribuir a controlar el cumplimiento de la Constitución, pero el Tribunal Constitucional lo hace de un modo especial, ya que examina la compatibilidad de toda la legislación vigente con la Constitución. La Constitución de 1997 o de la III República, es la fuente de Derecho más importante e indica las demás fuentes de Derecho, amén de su ámbito y carácter autónomo o ejecutivo respectivo. Los demás actos normativos subyacen en un status dependiente y concordante con el texto constitucional.

El Tribunal Constitucional supervisa la compatibilidad de los demás actos normativos con el texto constitucional, así como la conformidad del Derecho derivado con la legislación jerárquicamente superior. Por tanto, la supervisión del alto tribunal afecta a las leyes vinculadas al Capítulo X de la Finanzas Públicas, como por ejemplo la Ley de Presupuestos ${ }^{18}$.

La Constitución polaca establece una distinción entre la legislación de aplicación universal y las disposiciones de carácter interno. Los actos de aplicación universal son vinculantes para todas las entidades del país y regulan la situación jurídica de los ciudadanos y de otras entidades.

El artículo 91, apartado 3, del Capítulo III, de la Constitución define el papel del Derecho comunitario en el ordenamiento jurídico interno. El Derecho derivado de la UE es directamente aplicable y ostenta un rango superior en caso de conflicto de leyes ${ }^{19}$.

${ }^{18}$ Rozdział X, FINANSE PUBLICZNE, art. 216-227. Konstytucja Rzeczypospolitej Polskiej z dnia 2 kwietnia 1997.

http://isap.sejm.gov.pl/DetailsServlet?id=WDU19970780483. Consultado el 10 de diciembre de 2011.

${ }^{19}$ Trybunał Konstytucyjny w Polsce

Htpp://www.trybunal.gov.pl/index2.htm. Consultado el 10 de diciembre de 2011. 
El Derecho primario de la UE, forma parte del ordenamiento jurídico interno, es directamente aplicable y prima sobre el resto de la normativa, por tanto se puede afirmar que esto afecta de modo directo a los actos normativos con incidencia en el ámbito económico y presupuestario. Al hilo de la lógica jurídica anterior y en el supuesto de que un nuevo tratado de la UE, imponga la regla de oro a los Estados Miembros, se puede concluir que Polonia no deberá hacer una reforma constitucional, debido a que la Constitución de 1997 consagra todo un capítulo constitucional, el Capítulo $\mathrm{X}$ a esta cuestión.

Desde el artículo 118 al 124, del Capítulo IV, regulan la organización y funcionamiento de Cámaras de Diputados (Sejm) y del Senado, (Senat), que junto al Reglamento del Sejm y del Senat, determinan el procedimiento legislativo, que incide favorablemente en el control orientado a garantizar la traducción material de unos presupuestos, de finanzas públicas y de la deuda soberana ${ }^{20}$.

El derecho de iniciativa legislativa corresponde al Gobierno, a un grupo compuesto por un mínimo de quince diputados, al Senado, al Presidente de la República y a un grupo compuesto por un mínimo de 100000 ciudadanos. Las propuestas legislativas se presentan al Sejm, siendo objeto de tres lecturas. En el curso de este procedimiento, el Sejm examina la propuesta y la transmite a las comisiones parlamentarias competentes, después de lo cual vuelve al Sejm, que vota las enmiendas y el texto en su conjunto. El Sejm aprueba la propuesta por mayoría simple, siempre que esté presente al menos la mitad de los diputados. Una vez aprobada por el Sejm, se remite al Senado, que dispone de un mes para su adopción con o sin enmiendas, o para su rechazo en su totalidad. Si una propuesta fuese enmendada o rechazada por el Senado, ha de ser examinada nuevamente por el Sejm. En este caso, se necesita mayoría absoluta, siempre que esté presente al menos la mitad de los diputados, con el fin de superar el dictamen del Senado. Una vez concluido el procedimiento legislativo en el Parlamento, el texto se transmite al Presidente para su firma en el plazo de 21 días y posterior publicación en el Diario Oficial. Antes de la firma, el Presidente puede remitir el texto al Tribunal Constitucional para que verifique su constitucionalidad. Si al alto tribunal declara su constitucionalidad, el Presidente no puede negarse a la firma. El Presidente puede optar por no remitir el texto al Tribunal Constitucional y hacerlo al Sejm para una nueva lectura («veto presidencial»). Sin embargo, el Sejm puede rechazar un veto presidencial por una mayoría de $3 / 5$, siempre que esté presente al menos la mitad de los diputados. Si el texto fuese aprobado nuevamente por el Sejm, el Presidente tendrá un plazo de 7 días para proceder a la firma y ordenar su publicación ${ }^{21}$.

${ }^{20}$ Rozdział III, ŹRÓDŁA PRAWA, ART. 91, Konstytucja Rzeczypospolitej Polskiej z dnia 2 kwietnia 1997. http://isap.sejm.gov.pl/DetailsServlet?id=WDU19970780483. Consultado el 10 de diciembre de 2011.

21 PRZEBIEG PROCESU LEGISLACYJNEGO W SEJMIE http://www.sejm. gov.pl/prace/prace.html, http://www.sejm.gov.pl/Sejm7.nsf/kronika.xsp SessionID=D25N1 IT7QH, http://www.senat.gov.pl. Consultado el 16 de diciembre de 2011. 


\section{CAPÍTULO X: FINANZAS PÚBLICAS}

El articulado que compone el Capítulo X consagra la vigencia de la Regla de Oro, desde el artículo 216 hasta el artículo 224. El conjunto ha determinado en gran medida una tendencia positiva de la salud financiera polaca, aún en aquellas contingencias que imponen desviaciones de las previsiones de ingresos y gastos, según se desprende del articulado que compone el Capítulo X, titulado Finanzas Públicas. Llegado este punto y antes de adentrarnos en la cuestión específica económica financiera, resulta necesario destacar que los Estados Miembros de lo que fue la UE Quince no pusieron en valor los esfuerzos y sacrificios que revolución política y económica llevada a cabo por Polonia y los demás Estados de Europa Central desde 1989, un acontecimiento histórico cuyo alcance es desconocido para los ciudadanos de Europa occidental22.

\section{IV.1. Recursos, obligaciones, endeudamiento, préstamos, garantías y cauciones financieras}

El artículo 216 es significativo al respecto al establecer en su apartado 1 que los recursos financieros destinados a fines públicos serán obtenidos y gastados en el modo que la Ley los determine. El punto 3 del precepto, establece la misma orientación para la emisión de obligaciones por el Tesoro del Estado, el Banco Central de Polonia u otras personas jurídicas estatales.

Los apartados 4 y 5, del artículo 216 determinan los límites del endeudamiento público. La contratación de préstamos y la concesión de garantías y cauciones financieras por parte del Estado se realizan con arreglo a los principios y procedimientos establecidos en la ley, al tiempo que se impide que la contratación de prestamos, la concesión de garantías y cauciones financieras en virtud de las cuales la deuda pública del Estado pueda sobrepasar los tres quintos del valor del producto interior bruto interno anual. La prolijidad normativa del artículo 216, llega incluso a que se determine el método de cálculo del producto interior bruto anual y de la deuda pública por una ley específica ${ }^{23}$.

\section{IV.2. Ingresos del Estado y gestión de los activos del Tesoro}

En relación a los ingresos del Estado vía impositiva, el artículo 217, indica que el establecimiento de impuestos y gravámenes públicos, la determinación de los sujetos, de los bienes objeto de imposición y de las tarifas, así como los supuestos de desgravación, exención y condonación de deudas tributarias sean determinados por ley. La organización y el modo de gestión de los activos del Tesoro del Estado también quedan regulados por ley según el artículo 218.

\footnotetext{
${ }^{22}$ Geremek B. "La democracia en Europa”, Alianza Editorial, Madrid, 1992.

${ }^{23}$ Kosinski, E. "Prodecedura budzetowa a deficyt: Zagadnienia prawne na tle porównawczym”. Wydaawnictwo Sejmowe, Warszawa, 2001.
} 


\section{IV.3. Procedimiento legislativo y de ejecución de los Presupuestos}

El Sejm (Cámara de Diputados) aprueba el presupuesto del Estado para un año fiscal por medio de la ley de presupuestos (Artículo 219. 1). La ley determina los principios y procedimientos del proyecto de ley presupuestaria, el nivel de detalle de ésta y las condiciones en que debe satisfacer, así como los principios y el procedimiento para la ejecución del presupuesto del Estado (Art. 219.2).

La Constitución polaca de 1997 contempla supuestos excepcionales y de ralentización o bloqueo legislativo de la política presupuestaria. En estos casos establece que mediante un presupuesto provisional podrá determinar los ingresos y los gastos del Estado para un periodo inferior a un año. Los preceptos relativos al proyecto de ley de presupuestaria se aplican del modo conveniente al proyecto de esta ley provisional (Artículo 219.3). El punto 4 de este artículo dispone que si la ley presupuestaria o ley sobre el presupuesto provisional no han entrado en vigor el primer día del año fiscal, el Consejo de Ministros deberá dirigir las finanzas del Estado con arreglo al proyecto de ley en fase de tramitación.

\section{IV.4. Incrementos o reducciones de ingresos y la garantía de impedir desviaciones presupuestarias al alza}

La Carta Magna polaca también regula los incrementos o reducciones de ingresos, al tiempo que prevé contingencias de déficit presupuestario en el artículo 220 del Capítulo X, con una clara garantía de impedir desviaciones al alza. En relación a estas cuestiones cabe señalar que el apartado 1 del precepto establece que los incrementos del gasto o las reducciones de los ingresos planificados por el Consejo de Ministros no podrán conducir al Sejm (Cámara de Diputados) a aprobar un déficit presupuestario superior al previsto en el proyecto de ley presupuestaria. La prevención normativa de desviaciones que incrementen el déficit se cierra en el punto 2 del mismo artículo, al establecer que la Ley presupuestaria no puede prever la cobertura del déficit presupuestario mediante la asunción de obligaciones con el Banco Central del Estado.

\section{IV.5. Iniciativa legislativa presupuestaria exclusiva del Consejo de Mi- nistros}

Por su parte, el artículo 221 concede la iniciativa legislativa exclusiva al Consejo de Ministros en relación con la política presupuestaria, concretamente en lo relativo a ley de presupuestos, las leyes de presupuesto provisional, las enmiendas a la ley presupuestaria, la ley sobre emisión de deuda pública, y las leyes referentes a la concesión de garantías financieras por el Estado.

El Capítulo X pone un límite temporal al desempeño de la exclusiva iniciativa legislativa gubernamental en el ámbito presupuestario. En su artículo 222, determina que el Consejo de Ministros debe someter al Sejm (Cámara 
de Diputados) un proyecto de ley presupuestaria para el año siguiente no más tarde de los tres meses anteriores al comienzo del año fiscal. Sin embargo, la norma contempla supuestos excepcionales dentro de los cuales se prevé un plazo de presentación posterior no determinado. El Senat (Senado) está condicionado temporalmente en las aprobaciones de enmiendas de la ley presupuestaria con un plazo de 20 días desde su recepción, según lo establecido en el Artículo 223. Las limitaciones temporales del procedimiento legislativo también afectan al Jefe del Estado. En este sentido, cabe señalar que el Presidente de la República sancionará la ley de presupuestos o la ley del presupuesto provisional sometida a él o por el Presidente de la Cámara de Diputados dentro de los siete días siguientes a la fecha de su recepción, según el artículo 224. El precepto indica que lo establecido en el artículo 122 apartado 5 del Capítulo dedicado al Congreso y Senado, no será de aplicación a la ley presupuestaria, ni a la ley de presupuesto provisional ${ }^{24}$.

\section{IV.6. Supuesto de resolución sobre la constitucionalidad de la ley presu- puestaria y otras garantías preventivas}

La Constitución de la III República en su Capítulo X, incluye la contingencia relativa a que el Jefe del Estado solicite al Tribunal Constitucional una resolución sobre la constitucionalidad de la ley presupuestaria o ley del presupuesto provisional antes de sancionarla. En este supuesto, el Tribunal Constitucional debe resolver en un plazo máximo de dos meses, a contar desde el día en que fuere presentada la cuestión. (art. 224.2).

Las garantías preventivas frente a hipotéticos bloqueos legislativos en el ámbito presupuestario alcanzan un nivel máximo en el artículo 225, por el cual se establece que si transcurridos 4 meses desde la fecha en que el proyecto de ley presupuestaria fue presentado a la Cámara de Diputados, aquel no ha sido remitido al Presidente de la República para su sanción, éste podrá, en un plazo de 14 días, ordenar el acortamiento de la legislatura.

\section{IV.7. El control parlamentario de la ejecución del presupuesto}

El Capítulo X, no agota el rol legislativo del Sejm (Cámara de Diputados) en el proceso que da lugar a la vigencia de ley presupuestaria debido a que le otorga capacidad para ejercer una función de monitoreo y control de su ejecución, según se desprende del artículo 226.1. En este apartado la norma obliga al Consejo de Ministros, dentro de los cinco meses siguientes al término del año fiscal, a presentar a la Cámara de Diputados un informe sobre

${ }^{24}$ Rozdział IV, art.122, Sejm I Senat, en "Konstytucja Rzecypospolitej Polskiej z dnia 2 kwietnia 1997 r".: "Si el presidente de la República no recurre al Tribunal Constitucional, podrá devolver ley para su reconsideración a la Cámara de Diputados, acompañada de una solicitud fundamentada..." http://www.sejm.gov.pl/prawo/konst/polski/kon1.htm (Consultado el 14 de diciembre de 2011). 
la ejecución de la ley presupuestaria junto con información sobre la situación de la deuda soberana. El Sejm (Cámara de Diputados) examina la información recibida y, oída la opinión de la Cámara Superior de Control, procede a adoptar una resolución en la que aprueba o rechaza la Cuenta General del Estado presentada por el ejecutivo, dentro de los 90 días siguientes a la presentación del informe y de la información conexa, según lo determina el apartado 2 del artículo $226^{25}$.

\section{IV.8. El Consejo de Política Monetaria}

El Consejo de Política Monetaria está integrado por el Presidente del Banco Nacional de Polonia, que lo preside, así como por personas distinguidas por sus conocimientos en materia financiera que son nombradas, en igual número, por el Presidente de la República, el Presidente de la Cámara de Diputados (Sejm) y el Senado (Senat) para un periodo de seis años (art. 227.5). Este órgano fija anualmente las bases de la política monetaria e informa de ellas al Sejm, coincidiendo con la presentación del proyecto de ley presupuestaria que realiza el Consejo de Ministros. Otra función del Consejo de Política Monetaria es la de presentar a la cámara legislativa un informe sobre la ejecución de la política monetaria dentro de los cinco meses siguientes a la finalización del año fiscal. (art. 227.6).

\section{LOS PROCEDIMIENTOS DE REFORMA CONSTITUCIONAL GA- RANTIZAN LA VIGENCIA DE LA REGLA DE ORO}

El Capítulo XII, denominado Reforma de la Constitución, en su artículo 235 establece un procedimiento de reforma garante de su significado, de su forma y de su fuerza jurídica, que caracterizan al texto constitucional polaco como un referente dentro de la corriente constitucionalista liberal y progresista surgida tras la finalización de la segunda guerra mundial europea. El artículo 235 en su apartados 1-7 determina el procedimiento legislativo a seguir y que se distingue por la exigencia de mayorías reforzadas y otras regulaciones garantistas de los principios activos de la Carta Magna de 1997.

El apartado 1, del artículo 235 determina que el proyecto de reforma puede ser presentado por al menos un quinto del número total de diputados, el Senado o el Presidente de la República. La reforma constitucional exige la aprobación de una ley por la Sejm y el Senat, en un plazo de 60 días (art.235.2), debe ser aprobada por mayoría de dos tercios estando al menos presentes la mitad del número total de diputados, y por mayoría absoluta en el Senado, estando presentes la mitad del número total de senadores. (235.4). El apartado 3 del artículo 235 exige que la primera lectura del proyecto de ley sobre la reforma constitucional no podrá tener lugar dentro de los 30 días

${ }^{25}$ Kosikowski. C. "Finanse publiczne $w$ swietle Konstytucji RP, oraz orzecznictwa Trybunatu Konstytucyjnego”, Wydawnictwo Sejmowe, págs., Warszawa, 2004. 
siguientes a su presentación en el Sejm. Se puede concluir que los mecanismos de reforma establecidos en el artículo 235 garantizan el vigor y la precisión de los significados del Capítulo $\mathrm{X}$ diseñado para garantizar una tendencia de equilibrio de las finanzas públicas (artículos 216-227) ${ }^{26}$.

\section{EL NIK Y EL CONTROL DEL PROCESO PRESUPUESTARIO}

El Tribunal de Cuentas es junto al Tribunal Constitucional, el órgano de control más importante del país, también denominado NIK o Cámara superior de Control, según se establece en el Capítulo IX de la Constitución de 1997, consagrado a los órganos de Control Estatal y de Protección del Derecho ${ }^{27}$.

La tarea principal del NIK consiste en controlar la actividad de los órganos de Administración Pública, Banco Nacional de Polonia, personas jurídicas públicas y otras entidades públicas. El Tribunal de Cuentas puede asimismo controlar la actividad de los órganos de gobiernos territoriales, personas jurídicas de ámbito regional y otras entidades municipales ${ }^{28}$.

El origen de la Cámara Superior de Control se remonta a la época de la II República de Polonia, y es uno de los órganos más antiguos del Estado polaco. El NIK se creó el 7 de febrero de 1919, apenas tres meses después de que Polonia hubiese recuperado la independencia y su promotor fue el Mariscal Józef Piłsudski, Jefe de Estado en aquel momento. Desde el inicio de su andadura, el Tribunal de Cuentas fue el órgano principal de control del Estado capacitado para monitorear los gastos e ingresos del mismo y de cualquiera institución y empresa que se beneficiaran de los fondos públicos ${ }^{29}$.

En la actualidad el Tribunal de Cuentas o NIK está autorizado a realizar controles de todos los órganos del Estado polaco, de las delegaciones de la administración tanto centrales como locales, y de todas las empresas y entidades no oficiales que estén realizando contratos del Estado o disfrutando de

${ }^{26}$ Rozdział IX, ORGANY KONTROLI PAŃSTWOWEJ I OCHRONY PRAWA, art. 202-215, en "“'Konstytucja Rzecypospolitej Polskiej $z$ dnia 2 kwietnia 1997 ". (http://www.sejm.gov.pl/prawo/konst/polski/kon1.htm (Consultado el 14 de diciembre de 2011).

${ }^{27}$ Rozdział IX, Organy Kontroli Panstwowej I Ochorny Prawa, "Konstytucja Rzecypospolitej Polskiej z dnia 2 kwietnia 1997 r". : "La Cámara Superior de Control fiscaliza la actividad de los órganos de la Administración del Estado, del Banco Nacional de Polonia, de las personas jurídicas estatales y de otras unidades organizativas estatales en lo relativo a la legalidad, buena gestión, uso adecuado de los recursos y probidad. (art. 203.1)" http://www.sejm.gov.pl/prawo/konst/polski/kon1.htm (Consultado el 18 de diciembre de 2011)

${ }^{28}$ Rozdział IX , Organy Kontroli Panstwowej I Ochorny Prawa, "Konstytucja Rzecypospolitej Polskiej z dnia 2 kwietnia 1997 r" : "La Cámara Superior de Control puede fiscalizar la actividad de los órganos de la Administración territorial autónoma, de las personas jurídicas municipales en lo relativo a la legalidad, buena gestión y probidad. (art. 203.3)" (Consultado el 18 de diciembre de 2011).

${ }^{29}$ Oficjalny Portal Promocyjny Rzeczpospolitejrzeczy Posolitepolskiej, http://www. poland.gov.pl/ (Consultado el 18 de diciembre de 2011). 
las subvenciones y avales estatales. Según la normativa legal vigente, el Tribunal de Cuentas está sometido al control de la Cámara de los Diputados, que nombra al Presidente del Tribunal para un mandato de seis años, con previa aprobación del Senado. Conviene observar que el mandato del Presidente del Tribunal de Cuentas no coincide con el del Parlamento, lo cual en la práctica hace imposible que una sola opción política pueda influir en el Tribunal de Cuentas.

El Presidente del Tribunal también goza de inmunidad parecida a la de los diputados, ya que no puede ser arrestado ni acusado sin el consentimiento de la Cámara de los Dipùtados. El NIK realiza sus funciones por medio de delegaciones y departamentos y las divisiones departamentales reflejan los sectores o ámbitos sometidos a control.

El Tribunal de Cuentas puede iniciar sus actuaciones por iniciativa propia, por encargo de la Cámara de los Diputados, o de alguno de sus órganos como el Presidente de la Cámara. También puede intervenir por indicación del Jefe del Estado o del Jefe del Gobierno. El Tribunal de Cuentas presta una atención especial a la comprobación del grado de ajuste, tanto a los presupuestos del Estado como a los principales indicadores de la política financiera. El NIK elabora el informe previo a la aprobación de las cuentas estatales (absolutórium) que necesita obtener el Consejo de Ministros.

\section{CONCLUSIONES}

El proceso de transición democrática y económica polaca, junto al cumplimiento de los Criterios de Copenhague de 1993 y la exigencias del Tratado de Maastricht de 1992, contribuyeron a crear una condiciones objetivas favorables para que la Constitución de la III República de Polonia de 1997 consagre la Regla de Oro en su Capítulo X dedicado a la Finanzas Públicas.

Los procedimientos legislativos relativos a los presupuestos estatales, endeudamiento y política monetaria, contemplados en el Capítulo X de la constitución polaca han permitido establecer mecanismos de control de la formulación y ejecución de las políticas en esos ámbitos. Todo ello ha favorecido que Polonia haya sido uno de los países europeos que mejor ha resistido los efectos de la crisis económica desatada en 2008.

El Capítulo X y las directrices de la UE, han inducido a una política económica polaca que en los últimos años ha registrado un crecimiento medio del 3,5\%, muy por encima del retroceso del 0,6\% que tuvo la Unión Europea en el mismo periodo. Polonia ha sido además el único país del club comunitario que no entró en recesión en 2009, el peor año de la crisis financiera internacional. La clave ha estado en su dinámico sector exportador, en la fuerza del consumo y el gasto público, favorecido por los fondos europeos.

Sin embargo, la tendencia de equilibrio presupuestaria favorecida por el artículo 216 del Capítulo X es perfeccionable y su grado de efectividad se ha reducido por los efectos de la crisis durante 2011. La preocupación gubernamental es reducir el déficit fiscal. Los datos indican que el desequilibrio pú- 
blico de 2010 rondó entre el 7,4\% y el 7,9\% del PIB, un dato que supera en más de un punto el $6,8 \%$ de 2009. Por otro lado, la deuda pública alcanzó el $53 \%$ del PIB en 2010. El Ejecutivo polaco se comprometió con la Comisión Europea a reducir este desequilibrio al $5 \%$ en 2011 y al $2,9 \%$ en 2012. Las autoridades también presentaron un plan de austeridad de cuatro años mediante el cual se situaría la deuda pública por debajo del 50\% en 2014. Parte del desequilibrio que eleva el gasto público se debe a las reformas estructurales y el proceso de cohesión, económica, social y territorial, por tanto, se trata de un desequilibrio basado en una política de gasto responsable, antagónica al gasto superfluo o no estructural. Polonia es el mayor receptor de fondos comunitarios, acaparando en el periodo 2007-2013 un 20\% del total de la UE, hasta los 67.300 millones de euros. La financiación además de incrementar el desarrollo del país y las relaciones con sus socios comunitarios, ayuda a modernizar los principales sectores productivos polacos y preparar al país para su entrada en la Zona Euro, una vez superada la crisis.

En el año 2010 la actividad económica se incrementó debido a la confianza de los hogares y las empresas en el país. Cabe destacar que Polonia sigue siendo uno de los países más atractivos para los inversores. Un factor de gran importancia es la necesidad de mejorar la infraestructura, construcción de carreteras, ampliación de la red ferrocarril y la intensificación de trabajos relacionados con la introducción del euro en Polonia, prevista para 2014-2015. El PIB polaco estuvo creciendo hasta el año 2008 de una forma continua, sin embargo, el país no fue totalmente inmune a la crisis global, con unos efectos de empeoramiento del ritmo de esta tendencia ( $1,7 \%$ en 2009 y $4,2 \%$ en tres primeros trimestres de 2010) y un empeoramiento en el mercado laboral polaco.

Una consecuencia destacable del Capítulo X, es que Polonia no ha entrado en recesión durante la actual crisis financiera. La Comisión Europea le augura una proyección muy superior a la de España. Por eso está obteniendo el premio de los mercados, que están apostando por los países con cuentas saneadas y buenas perspectivas de crecimiento.

Polonia está bien situada en el ranking de probabilidad e impago de deuda soberana por país, según se desprende de los siguientes porcentajes es: Grecia $57.7 \%$, Irlanda $43.0 \%$, Portugal $40.1 \%$, España $18.9 \%$, Hungría $16.7 \%$, Rumanía $15.3 \%$, Latvia $15.0 \%$, Lituania $14.5 \%$, Bulgaria $13.5 \%$, Italia $12.5 \%$, Bélgica $11.8 \%$, Polonia $10.0 \%$. Sólo se encuentran en mejor posición que la deuda soberana polaca, las deudas de Alemania 4.0\%, Holanda 3.4\%, Dinamarca $3.4 \%$, Finlandia $2.6 \%$ y Suecia $2.5 \%{ }^{30}$.

${ }^{30}$ Guru Huky. Director de Inversiones en una compañía de Capital Riesgo, ha trabajado también como responsable de análisis de una Sociedad de Valores. MBA por el IE. http://www.gurusblog.com/archives/raning-paises-probabilidad-impago-deudasoberana/10/04/2011/ Consultado el 29 de noviembre de 2011. 
Los fondos estructurales de la UE también prestan apoyo a las inversiones en Polonia. No sólo directamente, sino también las inversiones indirectas, que ayudan a construir y modernizar las infraestructuras. El sistema de incentivos a la inversión y ayuda estatal en Polonia no se aplica a los sectores de fibras sintéticas, minería, industria siderurgia y de hierro, construcción naval, pesca y procesamiento y comercio de algunos productos agrícolas.

Actualmente existen 14 Zonas Económicas Especiales (ZEE) en Polonia, que ocupan más de 12.000 hectáreas y es previsible que sigan existiendo hasta 2015-2017, entre las que destacan: Legnica, Kamienna Góra y Walbrzych en la región de Dolnoslaskie; Lodz en la región de Lodzkie; Suwalki en la región de Podlaskie; Katowice en la región de Slaskie y Pomeranian en la región de Pomorskie. Según la Ley sobre actividades económicas, que entró en vigor el 1 de enero de 2001, los sujetos extranjeros pueden llevar a cabo actividades económicas estableciéndose en Polonia mediante las mismas formas legales que los empresarios polacos.

El sistema tributario de Polonia se ha adaptado en los últimos años a los de los vecinos de la UE. El tipo básico de IVA hasta el año 2010 era el 22\%. A partir del 1 de enero de 2011, Polonia ha elevado el IVA a 23\%. Existe un convenio firmado entre España y Polonia para evitar la doble imposición. Los ciudadanos comunitarios no precisan tarjeta de residencia. No obstante, para estancias mayores a 3 meses es preciso registrarse en el listado de comunitarios europeos. El registro es obligatorio y se realiza en la Presidencia de la Provincia (Voivodía). Polonia aplica la coordinación comunitaria de los sistemas de seguridad social para las personas que se desplazan dentro de la Unión (Reglamentos 1408/71 y 574/72).

El ministro polaco de Finanzas, Jacek Rostowski, sostuvo tras la Cumbre de Bruselas que la eurozona seguía sin tener estabilidad a pesar del reciente acuerdo alcanzado sobre la crisis de deuda soberana, y reconoció que pasarán varios años antes de que Polonia plantee de nuevo fechas concretas para su adhesión al Euro. Sin embargo, el país cumple las condiciones objetivas para entrar en el Euro desde 2008. 